\title{
Survival Analysis and Determinants of Timing of First Birth after Marriage in Nigeria
}

\author{
Adeniyi Francis Fagbamigbe ${ }^{1,2}$ and Erhabor Sunday Idemudia ${ }^{1}$
${ }^{1}$ School of Research and Postgraduate Studies (SoRPS), Faculty of Human and Social Sciences, North West University, Mafikeng, South Africa \\ ${ }^{2}$ Department of Epidemiology and Medical Statistics, Faculty of Public Health, College of Medicine, \\ University of Ibadan, Nigeria
}

\section{franstel74@yahoo.com}

\begin{abstract}
This study assessed the dynamics of First Birth Interval (FBI) after marriage, its determinants as well as relationship between fertility and $\mathrm{FBI}$ among women of reproductive age in Nigeria. We right-censored FBI of women aged 15-49 years using 2013 Nigeria DHS data, used Kaplan Meier survival function to monitor the timings and Cox Proportional Hazard (CPH) and Generalized Gamma (GG) regression to model factors affecting FBI. The median FBI in Nigeria was I.75 years and decreased with delayed age at marriage. Women with higher education have shorter $\mathrm{FBI}(\mathrm{TR}=0.86(95 \% \mathrm{Cl}: 0.85-0.88))$. Urban women were more likely to have earlier $\mathrm{FBI}(\mathrm{HR}=\mathrm{I} .2895 \% \mathrm{Cl}$ : I.24-I.32)). Fertility was significantly associated with $\mathrm{FBI}$. The longer the FBI the lower the fertility level and vice versa except for women aged 15-19 years. Age at marriage, educational attainment, wealth status and residence were the main determinants of timing of first birth after marriage in Nigeria.
\end{abstract}

Keywords: first birth interval, Cox proportional hazard, Generalized Gamma model, fertility.

\section{Introduction}

Across the globe, landmark reproductive events such as sexual debut, marriage, birth and pregnancy have been used by demographers to understand fertility behavior of women (Baschieri \& Hinde, 2007; Kumar \& Danabalan, 2006; Rasekh \& Momtaz, 2007; Shayan, Mohammad, Ayatollahi, \& Zare, 20l4). The time interval between marriage and first birth $(\mathrm{FBI})$ is prominent among the events and it could shape the reproductive characteristics and health as well as psychological behavior of women(Kumar \& Danabalan, 2006; Shayan et al., 20I4). It might also dictate the number of children a woman will have in her reproductive cycle. In contemporary African setting and in most developing countries, families, friends and couples usually expect first births within one year of marriage, after which they become apprehensive(Feng \& Quanhe, 1996). Early FBI has also been described as a way of showing that the woman is fertile (Gurmu \& Etana, 20I4).

Women's fertility and country's fertility level are affected by mirage of factors including availability of reliable birth control methods, religious beliefs, traditions and cultural norms, acceptability of abortion, age at marriage, infant mortality rate, educational and career development opportunities, economic factors, urbanization (Baschieri \& Hinde, 2007; Kumar \& Danabalan, 2006; Shayan et al., 2014). These factors could be categorized as cultural, social, economic and health factors. They operate through ratio of women in sexual unions, using contraception, who are not currently fecund and the level of induced abortion (John Bongaarts, 1978; Population Reference Bureau, 20I I; Suwal, 200 I).

FBI may determine women's reproductive patterns (Rasekh \& Momtaz, 2007) and also affect a country's fertility transitions. It is believed that women who had their first birth soon after marriage may have more births than equally fecund women who had delays. The shorter intergenerational time that results from high fertility due to short FBls from younger women could escalate a country's population growth (Baschieri \& Hinde, 2007; Kumar \& Danabalan, 2006; Shayan et al., 20l4).

While documented studies on $\mathrm{FBI}$ abounds in some parts of Africa (Baschieri \& Hinde, 2007; Gurmu \& Etana, 20I4) and also in the Middle East (Kumar \& Danabalan, 2006; Shayan et al., 2014) and in other parts of the world, such studies are relatively scarce in Nigeria. The study of marriage to first birth among women in Nigeria is crucial in ensuring better understanding of the dynamics of one of the determinants of population growth and to inform policy makers so as to channel appropriate efforts at controlling this major player in population growth. The burning question are: What is Nigeria's FBI? What are the factors affecting timing of first birth 
after marriage in Nigeria? What are the magnitudes of these effects in the presence of a censored data?

The primary aim of this paper is to examine the dynamics and factors that determine the interval between marriage and first birth and the interplay between this factors in the Nigerian context. Secondarily, we investigated relationship between timing of marriage and offered explanations attributing to such relationships. Besides documenting up to date information on dynamics and determinants of FBI in Nigeria, this study assessed the relationship between $\mathrm{FBI}$ and fertility among women. Unlike in most studies on FBI, which excluded married women without births, this current included all married women who participated in the survey as they all have inherent chances of giving births sometimes during their marriages. The information from both categories of women were used to arrive at our conclusions and the recommendations we made.

\section{Literature review and Theoretical Framework}

Demographic and socio-economic factors including mothers' education, residence, age at marriage, knowledge and use of contraceptives, employment status have been identified to influence FBI. These factors also include other socio-cultural factors such as race, values and norms (Baschieri \& Hinde, 2007; Feng \& Quanhe, 1996; Kumar \& Danabalan, 2006; Rasekh \& Momtaz, 2007; Shayan et al., 2014; Suwal, 200I). Education was found to have impacted FBI substantially with women having lower or no educational attainment to have births sooner than others(Feng \& Quanhe, 1996; Kumar \& Danabalan, 2006; Rasekh \& Momtaz, 2007; Rindfuss \& Hirschman, 1980; Rindfuss \& John, 1983; Shayan et al., 20I4). Nevertheless, a recent Ethiopian study has reported otherwise(Gurmu \& Etana, 20l4). The age at marriage has been identified as a determinant of timing of first births (Adebowale, Yusuf, \& Fagbamigbe, 2012; Feng \& Quanhe, 1996; Gurmu \& Etana, 20l4; Singh, Singh, \& Narendra, 20I0). Younger women often make reproductive decisions that could shorten $\mathrm{FBI}$ and other intervals and thereby increase fertility(Rasekh \& Momtaz, 2007).

However, Trussell et al (1985) in their study on "determinants of birth-interval length in the Philippines, Malaysia, and Indonesia: A hazard-model analysis" found that these factors do not have any independent effect on the birth intervals; rather, they influence fertility through proximate determinants of the birth interval such as breastfeeding, contraceptive use, coital frequency and induced abortion as illustrated in Figure I (Trussell et al., 1985).

Figure I: Theoretical and Empirical relationship between socio-demographic and other factors and Intervals between marriage and first birth

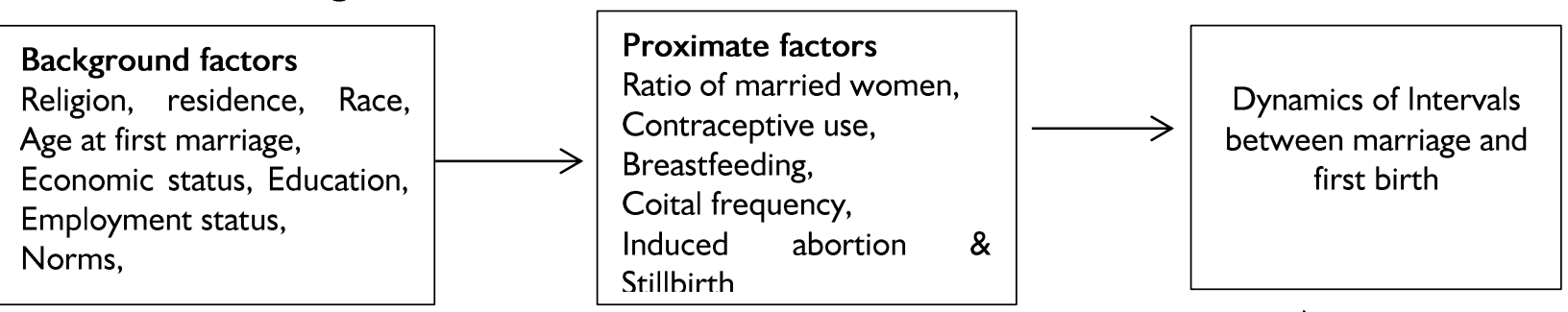

This theoretical and empirical relationship is intuitive as contraceptive use and its length of use play a critical role in $\mathrm{FBI}$ and fertility in general (Feng \& Quanhe, 1996). Other theories of fertility and other fertility determinants models have documented the role of contraceptive use in fertility outcomes (J. Bongaarts \& Feeney, 2006; John Bongaarts, 1978). Rural-urban differentials in respondents' place of residence also affected $\mathrm{FBI}$, the higher the development level of the region where a woman lives, the wider the FBls(Gyimah, 2008). However, the reverse could be the case as argued in an Indian study(Kumar \& Danabalan, 2006). The study cited fertility behavior of a woman who lives in rural area and her husband staying in urban area to make ends meet. The authors opined that such a woman is likely to have a prolonged FBI. This position was supported by findings of Ethiopian study which found a shorter $\mathrm{FBI}$ among urban women than rural women(Gurmu \& Etana, 20I4). Cultural practices and social custom could also significantly affect marriage to FB. Certain culture which requires the woman to spend some time with either her parent or husband's parents after marriage could lead to postponement of first births (Gurmu \& Etana, 20I4; Kumar \& Danabalan, 2006).

The analyses in this study was therefore hinged on the Trusell's theoretical and empirical relationship between socio-demographic and other factors intervals between marriage and first birth. To determine the $\mathrm{FBI}$ in this study, we linked the individual women's social and background characteristics to FBI through the proximate factors. 
The background characteristics were applied but the secondary nature of the data used for this study restricted us to using responses on haven had a pregnancy terminated and haven used something to prevent pregnancy as a proxy for contraceptive use.

Controlling fertility in Nigeria with FBI as a tool may check her population growth and improve her health outcomes. While the less developed countries accounted for over $80 \%$ of the world population by 2012, its annual infant death was 79:I compared to the developed countries.

The less developed countries, of which Nigeria is prominent, have a Gross National Income (GNI) Purchasing Power Parity (PPP) of \$I compared with $\$ 6$ in the most developed countries. Astronomical population growth in economically less developed countries could be linked with its high fertility. The Total Fertility Rate (TFR) of 2.6 among economically less developed countries is clearly above I.6 TFR prevalent in the most developed countries. Nigeria TFR of 5.6 exceeds the world average (2.4), Africa (4.7), sub-Sahara (5.I) and her natural increase rate of 2.6 doubled the global average of I.2 (FMoH, 2013; National Population Commission (Nigeria) and ICF International., 20I4; Population Reference Bureau, 20I2).

In this study we hypothesized that due to improved education coverage in the country(Ashir, Doctor, \& Afenyadu, 2013; Doctor, Bairagi, Findley, \& Helleringer, 20II; FMoH, 20I3; National Population Commission (Nigeria) and ICF International., 2014; National Population Commission (Nigeria) and ICF International, 2009), the FBI will be shorter among the better educated as higher educational attainment often increase age at first marriage(Adebowale, Fagbamigbe, Okareh, \& Lawal, 2012; FMoH, 20l3; National Population Commission (Nigeria) and ICF International., 20I4). However there could be interplay between education and other social changes such as marriage system, employment, sexuality, family planning etc. We also hypothesized that there is no association between women's FBI and number of children ever born. We controlled for the effects of individual woman's characteristics on a possible dependence between $\mathrm{FBI}$ and of timing of first marriage and make recommendations that could lower fertility in Nigeria.

\section{Data Sources and Methods Study design and setting}

We used the 2013 NDHS(National Population Commission (Nigeria) and ICF International., 20I4) data to answer questions surrounding FBls among women in Nigeria. The cross-sectional and nationally representative data provided up to date information about demographics and fertility of women of reproductive age in Nigeria. It engaged a four-stage sampling procedure. First stage was selection of local government areas on rural-urban basis from every state and the Federal Capital Territory (FCT), then selection of clusters, selection of households and lastly the selection of the individuals. The individuals were administered the pre-tested semi-structured questionnaires by well-trained interviewers and field supervisors during face-to-face interviews. A total of 38948 women age 15-49 were successfully interviewed. Written informed consent was given by participants for their clinical records to be used in the study.

\section{Data}

The respondents provided information on their background characteristics (age, religion, education etc.), reproductive history (time interval between marriage and first birth, age at first marriage and age at first birth) and children mortality, knowledge, source, and use of family planning methods. In this study, we defined marriage as any form of formal or informal consensual cohabitation between a man and woman (Measure DHS, 20II). Engaged partners were excluded in the analysis. We used time interval between marriage and first birth (FBI) as the dependent variable while geographical zones of residence, education, religion, residence, age at first marriage, husband education, type of family, age difference between husband and wife, if respondent ever had a terminated pregnancy or not and whether she has ever used something to prevent pregnancy used as independent variables. We dropped ethnic affiliation in the analysis as it was found to have strongly collinerity with religion affiliation and geographical zones of the women. Our choices of variables were based on the theoretical framework documented in Trusell et al (1985) and the findings in some previous studies (Adebowale, Yusuf, et al., 20I2; Feng \& Quanhe, 1996; Gurmu \& Etana, 20I4; Singh et al., 2010). Among the 38948 women who participated in the 2013 NDHS, 9820(25.2\%) who were never married, $871(2.2 \%)$ living with nonmarital partners, 1977(7.1\%) who had births before marriage and $3587(13.4 \%)$ who were pregnant before marriage (they reportedly had their first child before ninth month of marriage) were excluded from further analysis. Included in the analysis were the 22888 women who were married and either had first births after 8th month of marriage $(89.9 \%)$ or who have had no birth (10.1\%). We grouped $\mathrm{FBI}$ into 3 categories: before 1.5 years, 1.5-2.9 years and 3 years or thereafter as used in an Iranian study(Rasekh \& Momtaz, 2007). 


\section{Rationale for use of survival analysis}

Following up reproductive events in the life of a woman, although retrospectively, follows the fundamental principle of survival analysis. Survival analysis describes time duration to occurrence of an event of interest. Usually a follow up study might come to an end without every participant experiencing the event of interest such as first births after marriage been studied. Also, some participants might have been lost to follow up or probably withdrew from the study. The event of interest is said to be censored among these groups of participant and are included in the analysis. This is quite understandable because any of them could experience the event of interest immediately after the study or much longer. Their inclusion will overcome systematic bias as these participants could possess unique characteristics that could better explain the outcome of interest. In this study, the populations at risk are married women who had either given birth after marriage or who are likely to give birth at any time.

Survival analysis requires the survival time and censoring index to be well defined. In this study, we created a variable "censoring index" and coded it as "I" for those who had births and " 0 " for those who have not. The "survival time" among those who have not given birth is the time period between their dates of marriage and interview while time interval between marriage and first births were survival times for those with births. The survivor function $S(t)$ and hazard function $h(t)$ were used to determine the probability that a woman "survives" longer than some specified time $t$ before having a first birth and the instantaneous potential per unit time to have a first childbirth, given that the individual had not had a up to time $t$. Survival and hazard function are mathematically denoted by

$$
s(t)=S^{\prime}(t)=\frac{d}{d t} S(t)=\frac{d}{d t} \int_{t}^{\infty} f(u) d u=\frac{d}{d t}[1-F(t)]=-f(t) .
$$

and

$$
\lambda(t)=\lim _{d t \rightarrow 0} \frac{\operatorname{Pr}(t \leq T<t+d t)}{d t \cdot S(t)}=\frac{f(t)}{S(t)}=-\frac{S^{\prime}(t)}{S(t)} .
$$

In contrast to the survivor function $(s(t))$, which describes the probability of not experiencing the event of interest before time $t$, hazard function $(h(t))$ addresses the failure rate at time $t$ among those individuals who have not experienced the event at time $t$. Hazard function measures the potential for the event to occur at a particular time $t$, given that the event did not yet occur. Larger values of the hazard function indicate greater potential for the event to occur.

We used Kaplan-Meier estimator, developed for scenarios where survival time is measured on a continuous scale whereby only intervals containing an event contribute to the estimate, to compute the survival estimates. The Kaplan-Meier estimates of $\mathrm{S}(\mathrm{t})$ were obtained as

$$
s(t)=\prod_{j=1}^{k} \frac{\left(n_{j}-d_{j}\right)}{n_{j}}
$$

where $n_{j}$ is the number of subject observed at time $t_{j}$ and $d_{j}$ is the number of subject that experienced the event of interest at time $t_{j}$. The incidence rate (IR) of $\mathrm{FBI}$, which is the probability that a woman would have a first birth after marriage at time $t_{k+1}$ given that she has not had a child by time $t_{k}$, was also determined. It is the probability of first birth occurring after a particular interval (time after marriage) given that the woman has had no birth before then.
We model the determinants of $\mathrm{FBI}$ using the Cox Proportional Hazard (CPH) regression, developed by David Cox (Cox \& Oakes., 1983). The Cox model is in terms of hazard function which gives an expression for the hazard at time $t$ for an individual with a given specification of a set of independent variables denoted by $x$ to predict individuals' hazard. The model assumes the relationship for one covariate where $h_{o}(t)$ is the baseline hazard function, $x_{i}$ are the covariates and $\beta_{i}$ are the coefficients.

$h(t ; x)=h_{0}(t) \exp (x \beta)$

Cox regression estimates were stratified. In the stratified estimator, the hazard at time $t$ for a subject in group $i$ is assumed to be

$$
h_{i}(t)=h_{i 0}(t) \exp \left(\beta_{1} x_{i 1}+\ldots+\beta_{k} x_{i k}\right)
$$

The coefficients $\beta_{i}$ indicates whether the changes in the expected duration will be statistically significant or not. The hazard ratio (HR), expressed as the exponentials of the coefficients, implies more exposure to event of interest if it is $>I, H R<1$ means lower exposure while $H R=I$ has no effect on the exposure. Log rank test was used to compare the survival experience between different groups under study. Variables significant in the independent Cox 
regression were used in the multiple Cox regression while controlling for confounders.

We used the Generalized Gamma (GG) model, an accelerated failure time model, to check the performance of the $\mathrm{CPH}$. Beside been a parametric model, it has the advantage of estimating the coefficients more precisely and enhances easier interpretation over the Cox model, a semiparametric model. In parametric models, direct effects of the explanatory variables on the survival time are easily measured through "Time Ratio" (TR) instead of hazard. For each covariate in the model, a TR $>$ I implies that an individual experiences the event at a later timing and vice versa. We made provision for intra cluster correlation and also weighed the data to adjust for differences in population in each state and FCT. The use of the survival analysis approach in studies involving censored data is replete in literature (Adebowale, Fagbamigbe, et al., 2012; Adebowale, Yusuf, et al., 2012; Fagbamigbe, Adebowale, \& Morhason-Bello, 2015; Fagbamigbe \& Idemudia, 2016; Shayan et al., 20।4; Trussell et al., 1985).

We used two approaches to test the hypothesis of no association between women's FBI and number of children ever born. Firstly, we normalised the two variables because they violated normality assumptions and then used Pearson's correlation coefficient to determine strength and direction of association between the variables. Also, we evaluated the Chisquare significance of association between grouped FBI $(<1.5,1.5-2.9 \&>=3$ year) and number of children ever born (0, I-2, 3-4 \& 5+ births). The hypothesis were evaluated at each age of women involved in the study since fertility experience will be different at different reproductive age. Statistical significance was determined at $5 \%$ p-value. We used the Stata (version 13) statistical analysis software for all the data analysis.

\section{Ethical Consideration}

Ethical approvals for the study was sought and obtained from the Nigeria National Health Research Ethics Committee assigned number NHREC/0I/0I/2007 as earlier documented(National Population Commission (Nigeria) and ICF International., 20I4). Written informed consent was given by participants before the questionnaires were administered. Also, participant's personal information were anonymized and de-identified as the data was been collected prior to analysis. Written informed consent was given by participants for their clinical records to be used in the study.

\section{Results}

The history of first births among the 20596(89.9\%) women who had experienced at least a birth is shown in Table I. The median FBI was I.7 years (20 months), 2.I years among women who married before age 15 and 1.3 years among those who married after attaining age 25 years. The median FBI was 1.8 and 1.4 years in rural and urban areas respectively and 2.8 years among never educated women compared with 1.3 years among those with higher education. All the socio demographics of the respondents as well the spouses' characteristics were significantly associated with FBI.

Overall Median Survival Time (MST) to FBI was I.75 years ( 21 months) with 1.50 years in the urban areas and 1.92 years in the rural areas. Also, FBI MST was 1.33 years among women having higher education and 2.08 years among those who had no formal education, I.33 among women who had used contraceptives and 1.92 among those who didn't. The overall incidence rate (IR) of FBI, (risk of having a birth within a unit time) was $0.35,0.37$ among women of same age with their husband and 0.29 among women older than their husband.

In the bivariate analysis, the prognostic factors identified as significant by the CPH and GG regression models were similar. The GG showed that a woman with higher education has a shorter $\mathrm{FBI}$ than those with no education ( $\mathrm{TR}=0.86,95 \% \mathrm{Cl}$ : 0.85-0.88) while the CPH showed that risk of first birth after marriage was higher among women with higher education by $46 \%$ than uneducated women $(\mathrm{HR}=1.46,95 \% \mathrm{Cl}:$ I.38-I.54). The $\mathrm{CPH}$ showed higher risk of first birth after marriage among urban women than rural women $(\mathrm{HR}=1.28,95 \% \mathrm{Cl}$ : I.24I.32) with a corresponding TR of $0.94,95 \% \mathrm{Cl}: 0.93-$ 0.94) in the GG model (Table 2).

We present the patterns of the survival functions of $\mathrm{FBI}$ for the various factors considered in this study using the Kaplan Meier methods of survival estimation in Figure 2. The survival curves of respondents' $\mathrm{FBI}$ across the characteristics considered appeared similar but were found to be significantly different using long rank tests $(p<0.05)$. 
Figure I: The Kaplan Meier survival functions of FBI by Respondents' characteristics
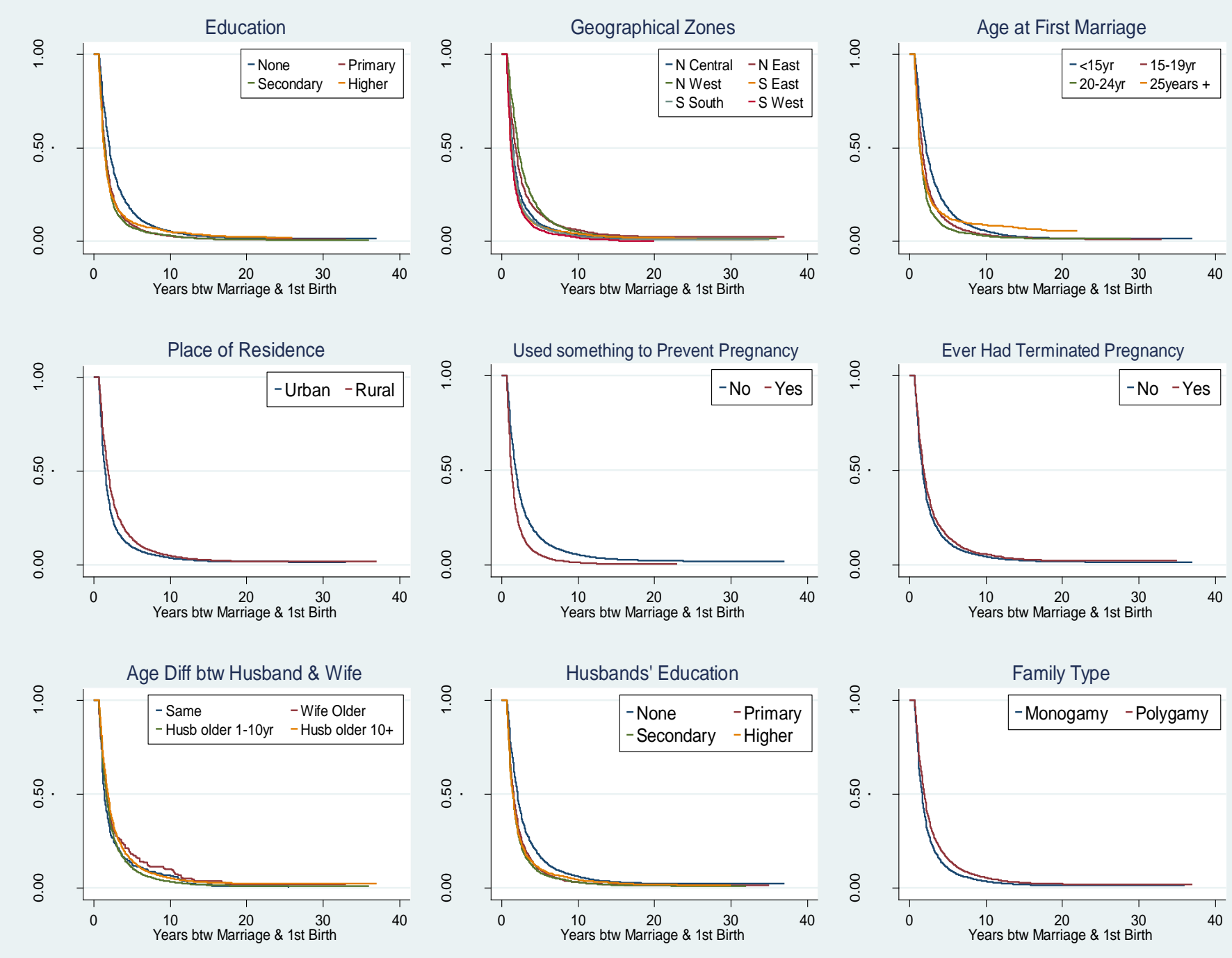

We fitted two models to control for the effects of the independent (background and proximate) factors in determining FBI in Nigeria. Model I consists of only the characteristics of women while Model 2 consists of Model I in addition to spouses' characteristics. In Model I, based on the GG model, women from North East (TR=1.04 95\% Cl: I.02-I.06) and North West $(T R=1.1395 \% \mathrm{Cl}$ : I.II-I.I5) had a prolonged first birth after marriage compared to those from the North Central while those from the South East ( $T R=0.9795 \% \mathrm{Cl}: 0.95-0.99)$ and South West ( $T R=$ 0.95 95\% Cl: 0.93-0.98) had a shorter FBI than in the North Central. This is similar to outcomes of the $\mathrm{CPH}$ model where women in North East and North West had higher risk of first birth after marriage than women in the North Central by $12 \%, \quad(H R=0.88$, $95 \% \mathrm{Cl}: 0.84-0.93)$ and $20 \%$ respectively compared to a shortened $\mathrm{FBI}$ in South East $(10 \%)$ and South West $(17 \%)$ than in the North Central. The risk of first birth after marriage decreased as women delayed marriage (HR=I.2I, 95\% Cl: I.I 7-I.25).

Addition of the husbands' characteristics in Model 2 did not improve the fitness of Model I. Based on GG model, family types and age differences between spouses were insignificant (Table 3).

The chi square test of hypothesis of no association between $\mathrm{FBI}$ and children ever born was statistically significant at all ages of women except at age 15. Also the Pearson's correlation coefficient showed that the longer the $\mathrm{FBI}$ the lower the fertility level and vice versa except for women aged 15-19 years, who seemed to have higher fertility with prolonged FBI (Table 4). We found association between number of children ever born and $\mathrm{FBI}$ among women aged 4044 years and $45-49$ years with correlation coefficient of -0.3185 and $\quad-0.34 \mid 4$ respectively. These categories of women were likely to have completed their family sizes. 


\section{Discussion}

In this study, we set to assess the dynamics of FBI among women of reproductive age in Nigeria and also identified the social-cultural factors influencing it.

The results showed that the average time between marriage and first birth after marriage among Nigerian women is 1.75 years (20 months). We found the determinants of first birth interval in Nigeria to include background, social and reproductive characteristics which consists of women's age at first marriage, place of residence, geographical zones of residence, women educational attainment, ever use of something to prevent getting pregnant and haven terminated a pregnancy. We also found that some women have waited for 25.5 years to have a first birth while some have been in-union for 37 years without a birth. Generally, we found that the longer the $\mathrm{FBI}$ the lower the fertility level of women and vice versa. Relationship between FBI and fertility was strongest among women who were likely to have completed their family size. While our study have been strengthened by use of large nationally representative data, it might be limited by its crosssectional nature. Data were self-reported and this could have been affected by recall bias.

The average $\mathrm{FBI}$ of 1.75 years found in this study was similar to 1.65 years reported in a similar study in India (Kumar \& Danabalan, 2006) but much higher than I.4 years in 1985 among women of reproductive age in China (Feng \& Quanhe, 1996). However, a recent African study reported a slightly longer $\mathrm{FBI}$ (I.92 years) in Ethiopia (Gurmu \& Etana, 20।4).

There were significant differences in median $\mathrm{FBI}$ across the respondents' characteristics. The median $\mathrm{FBI}$ decreased with delayed age at first marriage. We found women who married before attaining age 20 years to have a higher likelihood of prolonged FBI than those who married later. This was in concordance with reports of previous studies both in Africa and elsewhere (Feng \& Quanhe, 1996; Gurmu \& Etana, 20I4; Shayan et al., 20l4). This suggests that women who delayed marriage often start childbearing soon after marriage so as to make up for the late entry into motherhood. Nevertheless, we found fertility to be lower among women who married late and had a shortened FBI. Health, psychological and social-cultural factors might have affected women who married early than those who delayed marriage and thereby have prolonged FBI. Poor knowledge, anxiety, discomfort and undue interference from family members could have affected the preparedness of young girls to transit to early motherhood besides having reproductive health challenges such as fistula (Gurmu \& Etana, 20I4). This implied that delayed marriage may help reduce fertility rates.
The influence of educational attainment on FBI found in our study is in agreement with outcomes of previous studies (Eini-Zinab \& Agha, 2005; Feng \& Quanhe, 1996; Gurmu \& Etana, 20I4; Islam, 2009; Kumar \& Danabalan, 2006; Logubayom \& Luguterah, 2013; National Population Commission (Nigeria) and ICF International., 20I4). The studies have also reported prolonged $\mathrm{FBI}$ among women with low or no education than among respondents with higher education. The relationship between educational attainment and $\mathrm{FBI}$ is strong but indirect. The higher the educational attainment by married women the lower the FBI. This could be attributed to the fact that women with better education are more ready for marriage, better informed and also have better chance of choosing marriage partners which makes them to have quicker intimacy with partners and consequent shorter FBI (Gurmu \& Etana, 20I4).

Delayed marriage is strongly associated to longer years of education and a consequent lowered fertility. Closely related to role of educational attainment on $\mathrm{FBI}$ is the wealth status of the studied women on FBI. We found married women from wealthier households to have shortened FBI. The more educated a woman is, the more empowered she is through better job opportunity and a consequent better livelihood and a resultant shortened FBI and lowered fertility. Therefore, empowering women will delay first marriage and shorten $\mathrm{FBI}$ as well as lowering number of births.

First birth interval after marriage was more prolonged among women in rural areas than those in urban areas. The current finding is in agreement with findings of early study in Ethiopia (Gurmu \& Etana, 20I4) and China (Feng \& Quanhe, 1996). While the Ethiopian study reported a difference of $1 / 4$ year between rural and urban women, the Chinese study found that FBI was about 0.7 year longer for rural and coastal women as compared with upland and urban women. These differences could be ascribed to better preparedness for marriage among most women in urban areas than in rural areas and are therefore more ready for childbirth soon after marriage. Accessibility of better medical care in urban areas could have also influenced the differentials (Fagbamigbe \& Idemudia, 20I5a; Omo-Aghoja, Aisien, Akuse, Bergstrom, \& Okonofua, 2010). The prolonged timing of first births in rural areas among women who married at a younger age and are uneducated could be ascribed to high loss of pregnancy which is commoner among this class of women as a result of poor antenatal care (Babalola \& Fatusi, 2009; Lincetto, Mothebesoane-anoh, Gomez, \& Munjanja, 2010). 
This is intuitive because antenatal care use has been reported to be lower among less educated, poorer, younger and rural women especially from Northern part of Nigeria (Ashir et al., 2013; Doctor et al., 2011; Fagbamigbe, Akanbiemu, Adebowale, Olumide, \& Korter, 2013; Fagbamigbe, Bamgboye, et al., 20I5; Fatusi, 2009; FMoH, 20l3; National Population Commission (Nigeria) and ICF International., 20|4).

The wide difference could also be due to the fact that husbands often lives in urban cities to earn better livelihood while their wives are left behind in the rural areas thereby reducing the frequency of coitus and prolonging $\mathrm{FBI}$.

In the same vein, we found geographical differences in the rate at which women have first birth after marriage. Women from the North East and North West are likely to wait $20-30 \%$ longer than the women in the Southern axis of Nigeria waited to have first birth after marriage. Our finding agreed with outcome of previous studies elsewhere (Eini-Zinab \& Agha, 2005; Feng \& Quanhe, 1996; Kumar \& Danabalan, 2006). The situation in Northern Nigeria is understandable and anticipated. Previous studies are replete on the fact that child marriage is very prevalent in Northern Nigeria. These girls are betrothed to older men in most cases (Adebowale, Yusuf, et al., 2012; Doctor et al., 20I I). They might need long time to settle down to the forced marriage and understand their husband. Often, their bodies are not fully developed for reproduction and sometimes have to stay with husband's family at the early stage of marriage. All these contributes jointly and severally to prolonged FBI. However, the influence of types and geographical distribution of residence on $\mathrm{FBI}$ should be interpreted with caution as the roles of proximate factors is very evident here. Essentially, the age at first marriage, level of education and women empowerment have greater influence on $\mathrm{FBI}$ and fertility as earlier discussed.

Women in monogamy family have higher odds of early first birth after marriage than those in polygamous family. This could be as a result of the husband having alternative woman in his life. In Nigeria setting, husbands with multiple wives rarely keep them in the same household thereby making the men to have divided attention towards the wives. This finding is at variance with an India study which found average $\mathrm{FBI}$ of 1.3 years among women from extended families compared to a higher 1.58 years among women from nuclear families (Kumar \& Danabalan, 2006). Similarly, women who are of the same age with their husbands had a likelihood of earlier first birth after marriage than women younger or older than their husbands (Kumar \& Danabalan,
2006). The wider the age difference, the longer the FBI. This could be explained by the fact that more time may be needed to develop intimacy and regular coitus between partners with wider age difference.

Respondents who had ever used contraceptives had a shorter first birth interval than those who did not. On the contrary, women who had ever experienced pregnancy termination had likelihood of longer FBI. These scenarios are understandable since most contraceptives are used to temporarily prevent pregnancy and does not cause any permanent blockage while pregnancy termination could have hindered the chance and health of another conception since such women are at higher risk of complications resulting from earlier medical abortion(Roger Harms, 20I4; Shah \& Zao, 2009) and hence a prolonged FBI. The use of family planning techniques shortened $\mathrm{FBI}$ and was characterised by fertility reduction.

There was strong interplay among the determinants of $\mathrm{FBI}$ as reported in our study. It is noticeable that shorter $\mathrm{FBI}$ was commoner among women with higher education, urban dwellers and within highest wealth status. These are the categories of women who usually delay marriage (Adebowale, Fagbamigbe, et al., 20l2; FMoH, 20l3). They are thereby well prepared and ready for childbearing as soon as they get married both psychologically and financially and otherwise than other women. On the other hand, prolonged $\mathrm{FBI}$ has been associated with poorer women with lesser education and residing in rural areas. Considering geographical locations, $\mathrm{FBI}$ is more prolonged in Northern Nigeria, this is the area reputable for early girl marriage, low healthcare utilization and high health challenges among young women attending ANC(Fagbamigbe \& Idemudia, 20I5a, 20I5b).

\section{Conclusion and Recommendation}

Age at marriage, education, residence and other socio-demographic and reproductive characteristics of a woman are the main determinants of interval between marriage and first birth in Nigeria. Although delayed first birth after marriage may help reduce fertility, the fertility of women who delayed marriage will be lower irrespective of their first birth interval. Education and other means of social empowerment will help prolong marriage, shorten $\mathrm{FBI}$ and hence reduce fertility. There were strong interplays among these determinants. We recommend that education and social empowerment should be used as a strategy to improve social status of women so that age at first marriage could be postponed. This approach will serve as a means of promoting cultural changes and new orientation of youths on sexual and reproductive health and hence influence timing of 
marriage and fertility desire that could subsequently restructure first birth interval. This is informed by the established relationship between delayed age at first marriage, shortened first birth interval and low fertility. Prolonging first birth as fertility reduction strategy among women with low education and early marriage should be embraced by the policy makers and be guided by the differentials in sociodemographic and reproductive dynamics of Nigerian women.

\section{Contribution of Authors}

AFF conceived the study, designed the study, extracted, analysed the data and wrote the results of the analyses and discussion while ESI contributed to the introduction. Both authors reviewed the final version of the manuscript.

\section{Conflict of Interest}

Authors declared no conflict of interest

\section{Acknowledgements}

We acknowledge ICF macro and the National Population Council on behalf of the Federal government of Nigeria granting us access to the data used for this study

\section{References}

Adebowale, A. S., Fagbamigbe, A. F., Okareh, T. O., \& Lawal, G. O. (20I2). Survival Analysis of Timing of First Marriage among Women of Reproductive age in Nigeria: Regional Differences. African Journal of Reproductive Health, I6(4), 95-107.

Adebowale, A. S., Yusuf, B. O., \& Fagbamigbe, A. F. (20I2). Survival probability and predictors for woman experience childhood death in Nigeria: analysis of North-South differentials. BMC Public Health, I2(I), 430. http://doi.org//0.II86/I47I2458-I 2-430

Ashir, G. M., Doctor, H. V, \& Afenyadu, G. Y. (20I3). Performance Based Financing and Uptake of Maternal and Child Health Services in Yobe Sate , Northern Nigeria. Global Journal of Health Science; $\quad 5(3), \quad 34-41$. http://doi.org// 0.5539/gjhs.v5n3p34

Babalola, S., \& Fatusi, A. O. (2009). Determinants of use of maternal health services in Nigeria: looking beyond individual and household factors. BMC Pregnancy Childbirth, 9(43), 1-15.

Baschieri, A., \& Hinde, A. (2007). The proximate determinants of fertility and birth intervals in Egypt. Demographic Research, 16, 59-96. http://doi.org/10.4054/DemRes.2007.16.3

Bongaarts, J. (1978). A framework for analysing the proximate determinants of Fertility. Population and Development Review, 4, I05-32.
Bongaarts, J., \& Feeney, G. (2006). The quantum and tempo of life-cycle events. Vienna Yearbook of Population Research.

Cox, D. R., \& Oakes., D. (1983). The Analysis of Survival Data. (C. and Hall., Ed.). London: Chapman and Hall.

Doctor, H., Bairagi, R., Findley, S. E., \& Helleringer, S. (20II). Northern Nigeria Maternal, Newborn and Child Health Programme: Selected Analyses from Population-Based Baseline Survey. The Open Demography Journal, 4, I I-2 I.

Eini-Zinab, H., \& Agha, H.-Z. (2005). Demographic and Socio-Economic Determinants of Birth Interval Dynamics in Iran: A Hazard Function Analysis. In XXV General Population Conference of the International Union for the Scientific Study of Population (IUSSP) (pp. I-30). Tour, France.

Fagbamigbe, A. F., Adebowale, A. S., \& MorhasonBello, I. O. (20/5). Survival analysis of time to uptake of modern contraceptives among sexually active women of reproductive age in Nigeria. BMJ Open, $\quad 5(\mid 2), \quad \mid-8$. http://doi.org/|0.I I36/bmjopen-20|5-00837|

Fagbamigbe, A. F., Akanbiemu, F. A., Adebowale, A. S., Olumide, M. A., \& Korter, G. (20|3). Practice , Knowledge and Perceptions of Antenatal Care Services among Pregnant Women and Nursing Mothers in Southwest Nigeria. International Journal of Maternal and Child Health, I(I), 7-I6. http://doi.org//0.I2966/ijmch.

Fagbamigbe, A. F., Bamgboye, E. A., Yusuf, B. O., Akinyemi, J. O., Issa, B. K., Ngige, E., ... Abatta, E. (20I5). The Nigeria wealth distribution and health seeking behaviour: evidence from the 2012 national HIV / AIDS and reproductive health survey. Health Economics Review. http://doi.org//0.1 I86/s |356I-015-0043-9

Fagbamigbe, A. F., \& Idemudia, E. S. (2015a). Assessment of quality of antenatal care services in Nigeria: evidence from a population-based survey. Reproductive Health, I2(8), I-9. http://doi.org/I0.I I86/s I2978-0 I5-008I-0

Fagbamigbe, A. F., \& Idemudia, E. S. (20/5b). Barriers to antenatal care use in Nigeria: evidences from non-users and implications for maternal health programming. BMC Pregnancy and Childbirth, 15(95), I-I0. http://doi.org/I0.I I86/s I 2884-015-0527-y

Fagbamigbe, A. F., \& Idemudia, E. S. (2016). Survival analysis and prognostic factors of timing of first childbirth among women in Nigeria. BMC Pregnancy and Childbirth, 16(102), I-12. http://doi.org/I0.I I86/s I 2884-016-0895-y

Fatusi, A. O. (2009). Situation Analysis of Maternal, Newborn and Child Health Care in Ondo State. Abuja Nigeria. 
Feng, W., \& Quanhe, Y. (1996). Age at Marriage and the First Birth Interval: The Emerging Change in Sexual Behavior Among Young Couples in China. Population and Development Review, 22(2), 299 320.

FMoH. (20I3). National HIV/AIDS and Reproductive Health and Serological Survey, 20I2 (NARHS Plus),. Federal Ministry of Health, Abuja, Nigeria.

Gurmu, E., \& Etana, D. (20|4). Age at First Marriage and First Birth Interval in Ethiopia: Analysis of the Roles of Social and Demographic Factors. Afr Popul Stud, 28(3), 1332-1344. http://doi.org/http://dx.doi.org//0. I 1564/0-0-625

Gyimah, S. O. (2008). Polygynous marital structure and child survivorship in sub-Saharan Africa: Some empirical evidence from Ghana. Social Science \& Medicine, 68(2), 334-342. Retrieved from http://dx.doi.org//0.1016/j.socscimed.2008.09.06 7

Islam, S. (2009). Differential Determinants of birth spacing since Marriage to First Live Birth in Rural Bangladesh. Pertanika Journal of Social Science and Humanities, I 7(I), I-6.

Kumar, G. A., \& Danabalan, M. (2006). Determinants of Delayed First Birth. Indian Journal of Community Medicine, 3I(4), 4-5.

Lincetto, O., Mothebesoane-anoh, S., Gomez, P., \& Munjanja, S. (20l0). Antenatal Care: Opportunities for Africa's Newborns. New York. Retrieved from http://www.who.int/pmnch/media/publications/ao nsectionllI_2.pdf

Logubayom, I. A., \& Luguterah, A. (20I3). Survival Analysis of Time to First Birth after Marriage. Research on Humanities and Social Sciences, 3(I2), II 7-25.

Measure DHS. (20II). Age at First Marriage. Retrieved April 16, 2015, from http://www.measuredhs.com/help/Datasets/Age_ at_First_Marriage_Median_Age.htm

National Population Commission (Nigeria) and ICF International. (2009). Nigeria Demographic and Health Survey, 2008. DHS Measure Macro, New York and Nigeria Population Commission, Abuja, Nigeria.

National Population Commission (Nigeria) and ICF International. (20|4). Nigeria Demographic and Health Survey 2013. Abuja, Nigeria.

Omo-Aghoja, L. O., Aisien, O. A., Akuse, J. T., Bergstrom, S., \& Okonofua, F. E. (20I0). Maternal Mortality and Emergency Obstetric Care in Benin City South-South Nigeria. Journal of Clinical Medicine and Research, 2(4), 55-60.

Population Reference Bureau. (20II). Factors affecting Fertility. PRB, Washington.
Population Reference Bureau. (20/2). 2012 World Population Data Sheet. Retrieved November 12, 2015, from www.prb.org/pdfl l/world-womengirls-320770-data-sheet.pdf

Rasekh, A., \& Momtaz, M. (2007). The Determinants of Birth Interval in Ahvaz-Iran: A Graphical Chain Modelling Approach. Journal of Data Science, 5, 555-576.

Rindfuss, R. R., \& Hirschman, C. (1980). Social, Cultural, Economic Determinants of Age at Birth of First Child in Peninsular Malaysia. Population Studies, 34(3), 507-18.

Rindfuss, R. R., \& John, C. S. T. (1983). Social Determinants of Age at First Birth. Journal of Marriage and Family, 45(3), 553-565.

Roger Harms. (2014). Could an abortion increase the risk of problems in a subsequent pregnancy? Retrieved from http://www.mayoclinic.org/healthy-living/gettingpregnant/expert-answers/abortion

Shah, P. S., \& Zao, J. (2009). Induced termination of pregnancy and low birthweight and preterm birth: A systematic review and meta-analyses. International Journal of Obstetrics and Gynecology, I l6, I4-25.

Shayan, Z., Mohammad, S., Ayatollahi, T., \& Zare, N. (20|4). Prognostic factors of first birth interval using the parametric survival models. Iran J Reprod Med, I2(2), I25-130.

Singh, S. N., Singh, S. N., \& Narendra, N. (20l0). Demographic and Socio-economic Determinants of Birth Interval Dynamics in Manipur: A Survival Analysis. Online Journal of Health and Allied Sciences, 9(4), 1-5.

Suwal, J. V. (200I). Social-Cultural Dynamics of birth intervals in Nepal. Contributions to Nepalese Studies, 28(I), I I-33.

Trussell, J., Martin, L. G., Feldman, R., Palmore, J. A., Concepcion, M., \& Abu Bakar, D. (1985). Determinants of birth-interval length in the Philippines, Malaysia, and Indonesia: A hazardmodel analysis. Demography, 22(2), I45-68. 
Table I: Socio-demographic characteristics of married women with at least a birth in Nigeria

\begin{tabular}{|c|c|c|c|c|c|c|}
\hline & \multirow[b]{2}{*}{$\mathrm{n}$} & \multirow[b]{2}{*}{ Median } & \multirow[b]{2}{*}{ Max } & \multicolumn{3}{|c|}{$\mathrm{FBI}$ (years) } \\
\hline & & & & $<1.5 n=10076$ & $|.5-2.9 n=75| \mid$ & $3.0+n=5301$ \\
\hline \multicolumn{7}{|l|}{ Age at Ist marriage* } \\
\hline$<15$ & 6398 & 2.08 & 25.5 & 29.7 & 36.7 & 33.6 \\
\hline $15-19$ & 9308 & 1.58 & 22.9 & 44.1 & 36.3 & 19.7 \\
\hline $20-24$ & 3469 & 1.33 & 15.8 & 55.9 & 32.4 & 11.7 \\
\hline $25+$ & $|42|$ & 1.25 & 17.9 & 60.4 & 29.7 & 9.9 \\
\hline \multicolumn{7}{|l|}{ HW age difference* } \\
\hline Same & 213 & 1.33 & 25.5 & 58.4 & 24.4 & 17.3 \\
\hline Wife older & 177 & 1.67 & 17.3 & 42.7 & 33.0 & 24.3 \\
\hline Husb older I-10 & 11078 & 1.58 & 24.1 & 44.9 & 34.8 & 20.3 \\
\hline $\begin{array}{l}\text { Husb older II+" } \\
\text { Zone* }\end{array}$ & 7880 & 1.75 & 22.9 & 38.1 & 36.2 & 25.7 \\
\hline North Central & 3088 & 1.42 & 22.9 & 49.2 & 32.5 & 18.2 \\
\hline North East & 4163 & 1.75 & 24.1 & 40.5 & 34.7 & 24.8 \\
\hline North West & 7054 & 2.08 & 23.8 & 29.3 & 41.3 & 29.4 \\
\hline South East & 1702 & 1.25 & 25.5 & 60.6 & 28.3 & 11.1 \\
\hline South South & 2144 & 1.42 & 14.8 & 54.2 & 31.2 & 14.6 \\
\hline & 2445 & 1.25 & 15.3 & 61.3 & 27.2 & 11.5 \\
\hline Urban & \multicolumn{4}{|c|}{ Residence* } & 341 & 153 \\
\hline Rural & 3680 & 75 & 24. & 38.1 & 36.0 & 25.9 \\
\hline \multicolumn{7}{|l|}{ Education* } \\
\hline No education & 10276 & 2.00 & 24.1 & 33.1 & 37.4 & 29.6 \\
\hline Primary & 4292 & 1.42 & 25.5 & 49.7 & 33.3 & 17.0 \\
\hline Secondary & 4626 & 1.33 & 22.9 & 53.2 & 34.6 & 12.2 \\
\hline Higher & 1402 & 1.25 & 22.6 & 60.5 & 27.8 & 11.8 \\
\hline \multicolumn{7}{|l|}{ Husb Education* } \\
\hline No education & 8417 & 2.00 & 24.1 & 32.6 & 37.7 & 29.7 \\
\hline Primary & 3919 & 1.50 & 22.6 & 46.8 & 33.9 & 19.3 \\
\hline Secondary & 5294 & 1.42 & 25.5 & 51.1 & 34.1 & 14.8 \\
\hline Higher & 2765 & 1.42 & 22.9 & 52.6 & 32.4 & 14.9 \\
\hline \multicolumn{7}{|l|}{ Family type* } \\
\hline Monogamy & 12322 & 1.58 & 25.5 & 45.9 & 35.1 & 19.0 \\
\hline Polygamy & 7026 & 1.92 & 24.1 & 35.7 & 35.5 & 28.7 \\
\hline \multicolumn{7}{|l|}{ Religion } \\
\hline Catholics & 1938 & 1.33 & 22.1 & 56.4 & 28.1 & 15.5 \\
\hline Other Christian & 5928 & 1.33 & 25.5 & 55.6 & 28.9 & 15.5 \\
\hline Islam & 14676 & 1.92 & 24.1 & 36.4 & 35.1 & 28.4 \\
\hline Others & 352 & 1.70 & 18.1 & 44.5 & 34.7 & 20.8 \\
\hline \multicolumn{7}{|l|}{ Wealth Status } \\
\hline Poorest & 10944 & 2.0 & 24.1 & 34.3 & 35.1 & 30.6 \\
\hline Middle & 4111 & 1.5 & 25.5 & 48.6 & 30.5 & 20.9 \\
\hline Richest & 7833 & 1.4 & 22.6 & 52.8 & 31.2 & 16.0 \\
\hline \multicolumn{7}{|l|}{ Ever PP* } \\
\hline No & $|602|$ & 1.75 & 25.5 & 38.4 & 36.7 & 24.9 \\
\hline Yes & 4575 & 1.33 & 15.8 & 57.0 & 30.6 & 12.5 \\
\hline \multicolumn{7}{|l|}{ Ever HPT* } \\
\hline No & 17860 & 1.67 & 24.1 & 42.9 & 35.1 & 22.0 \\
\hline Yes & 2736 & 1.75 & 25.5 & 39.6 & 37.2 & 23.3 \\
\hline Total & 20596 & 1.67 & 25.5 & 42.5 & 35.3 & 22.2 \\
\hline
\end{tabular}

Table 2: Median survival times and Unadjusted Cox Proportional Hazard Model of relationship between FBI and respondents' characteristics

\begin{tabular}{lcccccc}
\hline & & & \multicolumn{2}{c}{ Cox Proportional } & \multicolumn{2}{c}{ Generalized Gamma Regression } \\
\cline { 5 - 7 } Characteristics & Incidence rate & Median ST & HR & $95 \% \mathrm{Cl}$ & TR & $95 \% \mathrm{Cl}$ \\
\hline Age at Ist marriage & & & & & & \\
$<15$ & 0.28 & 2.17 & Ref & & & \\
$15-19$ & 0.37 & 1.67 & 1.32 & $1.28-1.37^{*}$ & 0.91 & $0.90-0.92^{*}$ \\
$20-24$ & 0.46 & 1.42 & 1.66 & $1.59-1.73^{*}$ & 0.86 & $0.84-0.87^{*}$
\end{tabular}




\begin{tabular}{|c|c|c|c|c|c|c|}
\hline \multicolumn{7}{|l|}{$\begin{array}{l}25+ \\
\text { HW age Difference }\end{array}$} \\
\hline Same & 0.37 & 1.42 & 1.21 & I.06-1.39* & 0.94 & $0.89-0.98 *$ \\
\hline Wife Older & 0.29 & 1.75 & 0.98 & $0.85-1.14$ & 0.94 & $0.89-0.99 *$ \\
\hline Husband older 1-10 & 0.38 & 1.67 & 1.18 & $1 .|4-1.2|^{*}$ & 0.97 & $0.96-0.98 *$ \\
\hline $\begin{array}{l}\text { Husband older II+ } \\
\text { Zone }\end{array}$ & 0.32 & 1.92 & Ref & & & \\
\hline North Central & 0.40 & 1.50 & Ref & & & \\
\hline North East & 0.31 & 1.83 & 0.77 & $0.74-0.81 *$ & 1.08 & $1.06-1.10 *$ \\
\hline North West & 0.29 & 2.17 & 0.68 & $0.65-0.7 \mid *$ & 1.18 & $1.16-1.20 *$ \\
\hline South East & 0.44 & 1.33 & 1.14 & $1.08-\left.1.2\right|^{*}$ & 0.96 & $0.94-0.99 *$ \\
\hline South South & 0.45 & 1.42 & 1.09 & $1.03-1.15^{*}$ & 0.99 & $0.97-1.01$ \\
\hline South West & 0.51 & 1.25 & 1.28 & $1.21-1.35^{*}$ & 0.94 & $0.92-0.96 *$ \\
\hline \multicolumn{7}{|l|}{ Residence } \\
\hline Urban & 0.41 & 1.50 & 1.28 & I.24-1.32* & 0.94 & $0.93-0.95 *$ \\
\hline Rural & 0.33 & 1.92 & Ref & & & \\
\hline \multicolumn{7}{|l|}{ Wife Education } \\
\hline No education & 0.30 & 2.08 & Ref & & & \\
\hline Primary & 0.42 & 1.50 & 1.42 & I.37-1.47* & 0.90 & $0.89-\left.0.9\right|^{*}$ \\
\hline Secondary & 0.45 & 1.42 & 1.55 & 1.49-1.60* & 0.88 & $0.87-0.89 *$ \\
\hline Higher & 0.41 & 1.33 & 1.46 & I.38-I.54* & 0.86 & $0.85-0.88^{*}$ \\
\hline \multicolumn{7}{|l|}{ Husband Education } \\
\hline No education & 0.29 & 2.08 & Ref & & & \\
\hline Primary & 0.40 & 1.58 & 1.36 & $|.3|-|.4|^{*}$ & 0.91 & $0.9-0.92 *$ \\
\hline Secondary & 0.43 & 1.50 & 1.49 & I.44-I.54* & 0.89 & $0.88-0.9 *$ \\
\hline Higher & 0.40 & 1.50 & $\mathrm{I} .4 \mathrm{I}$ & I.35-I.47* & 0.89 & $0.87-0.9 *$ \\
\hline \multicolumn{7}{|l|}{ Family type } \\
\hline Monogamy & 0.38 & 1.67 & 1.23 & $1.19-1.26 *$ & 0.95 & $0.94-0.96 *$ \\
\hline Polygamy & 0.31 & 1.92 & Ref & & & \\
\hline \multicolumn{7}{|l|}{ Religion } \\
\hline Catholics & 0.42 & 1.33 & Ref & & & \\
\hline Other Christian & 0.45 & 1.42 & 1.04 & $0.98-1.07$ & 1.00 & $0.98-1.02$ \\
\hline Islam & 0.31 & 2.00 & 0.69 & $0.65-0.72 *$ & 1.13 & $1.11-1.16^{*}$ \\
\hline Others & 0.36 & 1.75 & 0.81 & $0.72-0.91 *$ & 1.06 & $1.01-\left.1.1\right|^{*}$ \\
\hline \multicolumn{7}{|l|}{ Wealth Status } \\
\hline Poorest & 0.29 & 2.08 & Ref & & & \\
\hline Middle & 0.39 & 1.5 & 1.34 & $1.29-1.38 *$ & 0.91 & $0.90-0.93 *$ \\
\hline Richest & 043 & 1.42 & $\mathrm{I} .47$ & $1.42-1.52 *$ & 0.89 & $0.88-0.90 *$ \\
\hline \multicolumn{7}{|l|}{ Ever PP } \\
\hline No & 0.32 & 1.92 & Ref & & & \\
\hline Yes & 0.52 & 1.33 & 1.64 & I.58-I.69* & 0.91 & $0.90-0.92 *$ \\
\hline \multicolumn{7}{|l|}{ Ever HPT } \\
\hline No & 0.35 & 1.75 & 1.12 & $1.07-1.16 *$ & 0.99 & $0.98-1.01$ \\
\hline Yes & 0.32 & 1.92 & Ref & & & \\
\hline Total & 0.35 & 1.75 & & & & \\
\hline
\end{tabular}

TR Time Ratio, HR Hazard Ratio ST Survival Time HW Husband-Wife HPT Had pregnancy terminated *Significant at 5\%

Table 3: Multiple Survival analysis Regression Model of FBI using the CPH and GG

\begin{tabular}{|c|c|c|c|c|c|}
\hline \multirow[b]{2}{*}{ Characteristics } & \multicolumn{3}{|c|}{ Model I } & \multicolumn{2}{|c|}{ Model 2} \\
\hline & & Cox Regression & Generalized Gamma & Cox Regression & Generalized Gamma \\
\hline $\begin{array}{l}\text { Age at Ist marriage } \\
<15 \\
15-19 \\
20-24 \\
25+\end{array}$ & $\begin{array}{r}\text { HR } \\
* 1.21 \\
* 1.28 \\
1.05 \\
\text { Ref }\end{array}$ & $\begin{array}{l}95 \% \mathrm{Cl} \\
\mathrm{I} .17-\mathrm{I} .25 \\
\mathrm{I} .23-\mathrm{I} .35 \\
0.98-\mathrm{I} .12\end{array}$ & $\begin{array}{cc}\text { TR } 95 \% \mathrm{Cl} \\
* 0.940 .93-0.95 \\
* 0.93 & 0.91-0.94 \\
* 0.94 & 0.92-0.97\end{array}$ & $\begin{array}{rl}\mathrm{HR} & 95 \% \mathrm{Cl} \\
* 1.20 & \mathrm{I} .16-\mathrm{I}-25 \\
* 1.29 & \mathrm{I} .23-\mathrm{I} .35 \\
\mathrm{I} .07 & \mathrm{I} .00-\mathrm{I} .14\end{array}$ & $\begin{array}{rl}\text { TR } & 95 \% \mathrm{Cl} \\
* 0.93 & 0.92-0.95 \\
* 0.92 & 0.90-0.94 \\
* 0.94 & 0.92-0.97\end{array}$ \\
\hline
\end{tabular}




\section{Zone}

North Central

North East

North West

South East

South South

South West

Residence

Urban

Rural

Wife Education

No education

Primary

Secondary

Higher

Religion

Catholics

Other Christian

Islam

Others

Wealth Status

Poorest

Middle

Richest

Ever PP

No

Yes

Ever HPT

No

Yes

HW

Same

Wife Older

Husband older I-

Husband older

Husband Education

No education

Primary

Secondary

Higher

Family type

Monogamy

Polygamy

2loglikelihood

|.|2-|.2|

I.08-I.18

$0.97-1.10$

*0.95 $0.94-0.97$

*0.96 0.94-0.98

*0.95 $0.93-0.98$

$* 1.12$ I.07-I.I7

$* 1.07$ I.02-I.13

I.0I 0.94-I.10

Ref

1.03

*0.67

\section{$0.98-1.07$}

$0.65-0.72$

$0.72-0.91$

$\begin{array}{llr}1.00 & 0.98-1.02 & 1.02 \\ 1.13 & 1.11-1.16 & * 0.65 \\ 1.06 & 1.01-1.11 & * 0.80\end{array}$

$0.98-1.07$

$0.65-0.72$

$0.72-0.91$

Ref

*1.24

*1.37

1.29-1.39

$\begin{array}{lll}0.90 & 0.90-0.92\end{array}$

*I.34

|.29-1.38

$\begin{array}{lll}0.87 & 0.88-0.90\end{array}$

*1.47

I.42-1.52

Ref

*1.32

* I. 22

Ref

$$
\text { I.27-I.37 }
$$

*0.96 $0.95-0.98$

*I.3। $1.26-1.36$

*0.97 $0.95-0.98$

I.17-I.27

$0.970 .95-0.98$

*I.23 I.18-1.28

$1.00 \quad 0.87-1.15$

*0.82 $0.70-0.95$

*I.05 I.02-I.08

Ref

Ref

*I.09 1.04-I.14

*1.10 1.05-1.16

I.04 0.99-I.II

*I.07 I.03-I.10 Ref

1.05 I.0I-I.II
$0.91 \quad 0.90-0.93$

$0.89 \quad 0.88-0.90$

*1.03 I.01-I.06

$* .12$ I.I0-I.15

*0.97 0.94-I.0I

I.00 0.98-I.03

*0.95 $0.93-0.97$

*0.98 $0.97-0.99$

*0.96 $0.95-0.98$

*0.97 $0.95-0.99$

*0.97 $0.93-0.99$

$0.99 \quad 0.98-1.01$

1.10 I.II-I.15

*0.96 $\quad 0.94-0.97$

*0.96 $0.94-0.98$

$0.97 \quad 0.92-1.03$

$0.970 .91-1.03$

$0.990 .98-1.00$

$0.980 .96-1.00$

$0.970 .95-1.00$

$0.97 \quad 0.95-1.00$

$1.000 .98-1.01$

*Significant at 5\%. HW Husband-Wife HPT Had pregnancy terminated PP Used something to prevent

Table 4: Relationship between womens'first birth interval and number of children ever born according to current age of women

\begin{tabular}{|c|c|c|}
\hline Age of Ever Married Women (year) & Correlation Coefficient* & Chi-square $\left(x^{2}\right)$ p-value $^{\wedge}$ \\
\hline $\begin{array}{l}15 \\
16 \\
17 \\
18 \\
19 \\
\end{array}$ & $\begin{array}{r}0.1478 \\
0.2600 \\
0.0337 \\
0.0513 \\
0.0223 \\
\end{array}$ & $\begin{array}{l}0.005^{\wedge} \\
<0.001 \wedge \\
<0.001 \wedge \\
<0.001 \wedge \\
<0.001 \wedge \\
\end{array}$ \\
\hline $15-19$ & 0.1357 & $<0.001^{\wedge}$ \\
\hline $\begin{array}{l}20 \\
21 \\
22 \\
23 \\
24 \\
\end{array}$ & $\begin{array}{l}-0.1609 \\
-0.1376 \\
-0.0897 \\
-0.1756 \\
-0.0897 \\
\end{array}$ & $\begin{array}{l}<0.001 \wedge \\
<0.001 \wedge \\
<0.001 \wedge \\
<0.001 \wedge \\
<0.001 \wedge\end{array}$ \\
\hline $20-24$ & -0.1304 & $<0.001^{\wedge}$ \\
\hline
\end{tabular}


African Population Studies Vol 30, No 2 (Supp), 2016

\begin{tabular}{|c|c|c|}
\hline $\begin{array}{l}25 \\
26 \\
27 \\
28 \\
29 \\
\end{array}$ & $\begin{array}{l}-0.2269 \\
-0.0687 \\
-0.1037 \\
-0.1998 \\
-0.0985 \\
\end{array}$ & 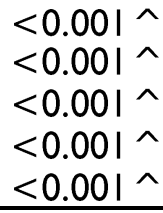 \\
\hline $25-29$ & -0.1592 & $<0.001^{\wedge}$ \\
\hline $\begin{array}{l}30 \\
31 \\
32 \\
33 \\
34 \\
\end{array}$ & $\begin{array}{l}-0.3470 \\
-0.2131 \\
-0.2241 \\
-0.2404 \\
-0.2687 \\
\end{array}$ & $\begin{array}{l}<0.001 \wedge \\
<0.001 \wedge \\
<0.001 \wedge \\
<0.001 \wedge \\
<0.001 \wedge\end{array}$ \\
\hline $30-34$ & $-0.287 \mid$ & $<0.001^{\wedge}$ \\
\hline $\begin{array}{l}35 \\
36 \\
37 \\
38 \\
39 \\
\end{array}$ & $\begin{array}{l}-0.3259 \\
-0.3407 \\
-0.2811 \\
-0.1509 \\
-0.2470\end{array}$ & $\begin{array}{l}<0.001 \wedge \\
<0.001 \wedge \\
<0.001 \wedge \\
<0.001 \wedge \\
<0.001 \wedge\end{array}$ \\
\hline $35-39$ & -0.3259 & $<0.001^{\wedge}$ \\
\hline $\begin{array}{l}40 \\
41 \\
42 \\
43 \\
44 \\
\end{array}$ & $\begin{array}{l}-0.3799 \\
-0.3287 \\
-0.2572 \\
-0.2268 \\
-0.2598\end{array}$ & $\begin{array}{l}<0.001 \wedge \\
<0.001 \wedge \\
<0.001 \wedge \\
<0.001 \wedge \\
<0.001 \wedge\end{array}$ \\
\hline $40-44$ & -0.3185 & $<0.001^{\wedge}$ \\
\hline $\begin{array}{l}45 \\
46 \\
47 \\
48 \\
49\end{array}$ & $\begin{array}{l}-0.3456 \\
-0.3548 \\
-0.3692 \\
-0.3392 \\
-0.3125\end{array}$ & $\begin{array}{l}<0.001 \wedge \\
<0.001 \wedge \\
<0.001 \wedge \\
<0.001 \wedge \\
<0.001 \wedge\end{array}$ \\
\hline $45-49$ & $-0.34 \mid 4$ & $<0.001^{\wedge}$ \\
\hline Total & -0.1017 & $<0.001^{\wedge}$ \\
\hline
\end{tabular}

*Pearson's correlation coefficient of relationship between womens' normalised $\mathrm{FBI}$ and children ever born

**Significant Chi-square test of association between grouped $\mathrm{FBI}(<1.5,1.5-2.9 \& 3+$ year $)$ and number of children ever born (0, I-2, 3-4 \& 5+ births) 